\title{
GUITAR AUDIO AMPLIFIER USING IC LM386
}

\author{
A. C. GHEORGHE \\ Department of Electronics, Telecommunications and Energy Engineering, Valahia University of Targoviste \\ E-mail: gheorghe_andrei89@yahoo.com
}

\begin{abstract}
The paper proposes the development of a guitar audio amplifier that is made from a low-priced IC LM386 chip, this amplifier can also be used for radios and other electronic projects. IC LM 386 is a reliable and versatile chip that can be used even to make an oscillator that can output sine or square waves. The purpose behind developing this guitar audio amplifier is to offer an easy and economical way to build a good sounding amplifier.
\end{abstract}

Keywords: amplifier, LM386, economical

\section{INTRODUCTION}

The paper proposes the development of a guitar audio amplifier that is made from a low-priced IC LM386 chip and also can be used for radios and other electronic projects [1]. IC LM 386 is a reliable and versatile chip that can be used even to make an oscillator that can output sine or square waves and this chip is the most common amplifier that is used in Do It Yourself (DIY) projects for developing an electric guitar amp because it can run on an 9 Volt battery. The purpose behind developing this guitar audio amplifier is to offer an easy and economical way to build a good sounding amplifier. The amplifier is made out of this components:

- IC LM 386 that has 8 pin dual in-line (DIP-8) package and the output of the chip is from 0.25 to 1 watt of power, this output depends on the model of the 9V supply. The IC operates between $4 \mathrm{~V}$ and $12 \mathrm{~V}$ of power and has the load impedance of $8 \mathrm{Ohms}$.

- Capacitors ( 8 capacitators to be exact) that are in the range of $470 \mathrm{pF}-1000 \mu \mathrm{F}$ of capacity.

- Resistors, 2 fixed resistors with $10 \Omega$ and $10 \mathrm{k} \Omega$ resistance and 3 variable resistors (potentiometers).

- Basic speaker that has the output of 0.5 Watts and the load impedance of $25 \Omega$

- A alkaline battery that offers the power that we need to use the amplifier, the battery output is $9 \mathrm{~V}$.

\subsection{IC LM 386}

The LM386 (Figure 1) is a low-priced power amplifier that is designed for use in low voltage consumer applications. The amplifier has the gain set internally to 20 to keep the count low for the external part, but if the user will add an external resistor and capacitor between the pins 1 and 8 this will increase the gain in the range of 20 to 200. The inputs of the amplifier are ground referenced and the output automatically biases to one-half of the supply voltage [2]. The quiescent power drain is very low (only $24 \mathrm{~mW}$ ) when operating from a $6 \mathrm{~V}$ supply, making the LM386 ideal for operating from a battery supply.

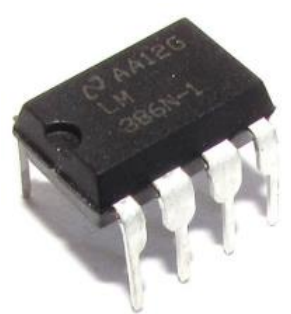

Figure 1. IC LM 386

In the Figure 2 we can see the pin diagram of the LM386.

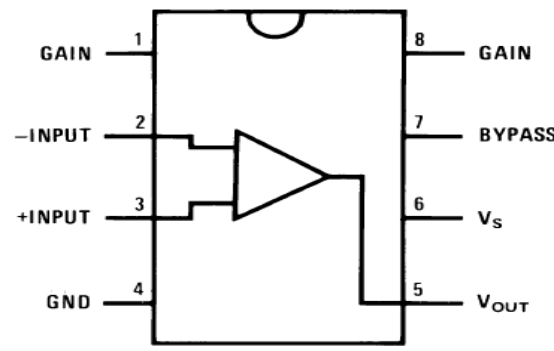

Figure 2. IC LM 386 Pin Diagram

\subsection{Capacitors and resistors}

In Figure 3 we have the capacitators and resistors that are used to build the guitar audio amplifier. The circuit is made from 2 types of capacitators, electrolytic and polypropylene and 5 resistors where three of them are variable resistors that are used for gain, volume and bass settings.

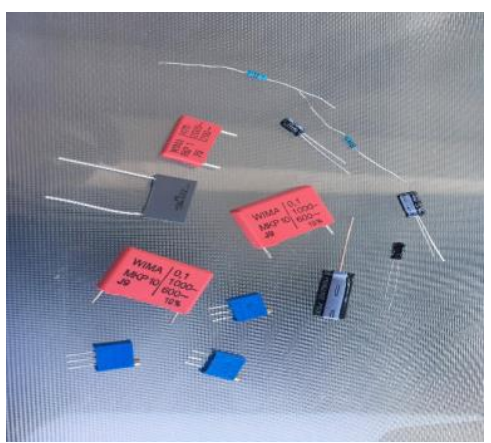

Figure 3. Capacitators and Resistors used to build the amplifier

\subsection{Basic speaker and battery}

In Figure 4 we can see the speaker and battery used for this amplifier, the speaker has an output of $0.5 \mathrm{~W}$ with a load impedance of $25 \Omega$ and for the power supply we used a common $9 \mathrm{~V}$ battery. 


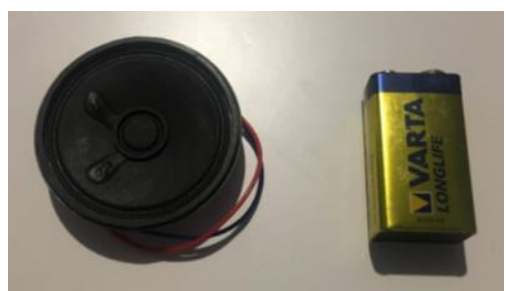

Figure 4. Basic speaker and battery

\section{GUITAR AUDIO AMPLIFIER}

In Figure 5 we have the first version of the amplifier, we have just one variable resistor for the volume setting and two capacitators. The design is a basic one that needs improvement for a better sounding amplifier.

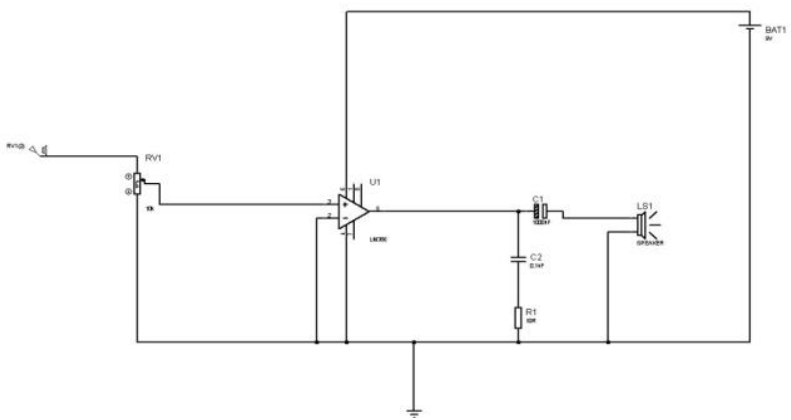

Figure 5. Audio Amplifier Schematic v1.0

In Figure 6 we have the schematic for our final version of the amplifier [3]. The circuit now contains some improvements:

- One capacitor $(470 \mathrm{pF})$ that is placed between the positive input signal and ground, which filters out the radio noise from the input wires.

- $\quad$ Two capacitors (one with an $100 \mu \mathrm{F}$ and the other with $0.1 \mu \mathrm{F}$ capacity). The capacitors are placed between the + and - power rails to decouple the power supply. The $100 \mu \mathrm{F}$ capacitor is there to filter out low frequency noise and the $0.1 \mu \mathrm{F}$ capacitor will be used to filter out high frequency noise.

- One capacitator with $0.1 \mu \mathrm{F}$ capacity that is placed between pin 4 and pin 6 , for extra decoupling of the power supply to the chip.

- A resistor $(10 \mathrm{k} \Omega)$ and a capacitor $(10 \mu \mathrm{F})$ that are placed in series between pin 7 and ground to decouple the input signal from the audio port.

A extra capacitor with a value of $0.033 \mu \mathrm{F}$ and a potentiometer $(10 \mathrm{k} \Omega)$ that are placed in series between pins 1 and 5 that is used for bass setting.

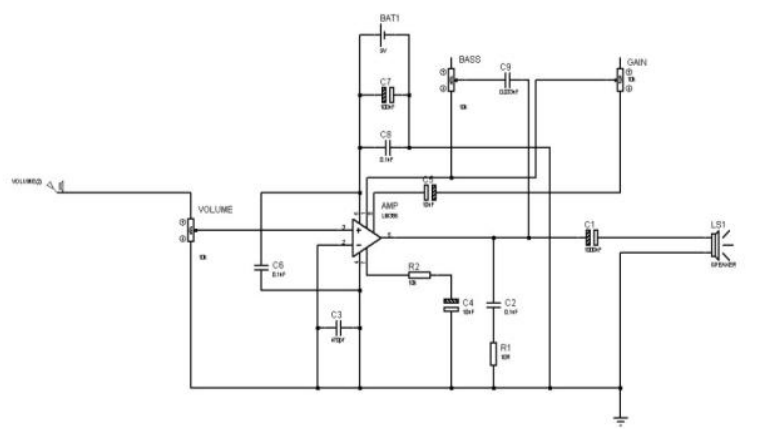

Figure 6. Audio Amplifier Schematic v2.0

In Figure 7 we have the first prototype of the amplifier, the amp has 3 potentiometers where the user can fine tune the volume, gain and bass of the amplifier, the audio input is made from an standard $3.5 \mathrm{~mm}$ jack cable [4].

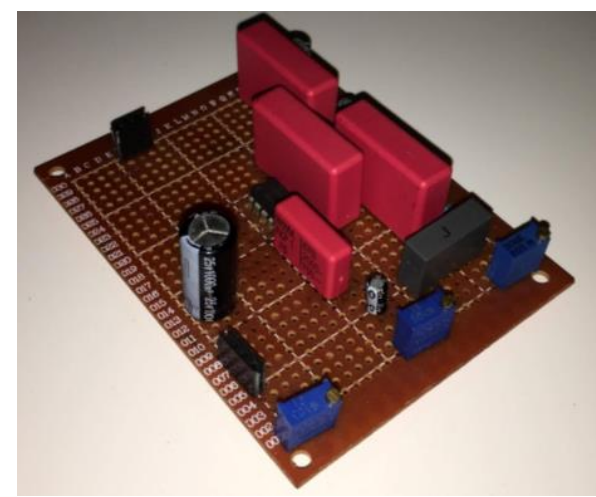

Figure 7. Prototype of the guitar amplifier

In Table 1 we have the total cost that is required for buying all your parts that are need to build this guitar amplifier.

Table 1. Price list for the part used to make the amplifier

\begin{tabular}{|c|c|}
\hline Parts & Price \\
\hline LM386 & 2 \\
\hline Capacitors & 15 \\
\hline Resistors & 0.2 \\
\hline Potentiometers & 2 \\
\hline Speaker & 3 \\
\hline Battery & 2 \\
\hline Misc & 3 \\
\hline TOTAL & 27.2 Euro \\
\hline
\end{tabular}

\section{CONCLUSIONS}

The guitar audio amplifier is far from the best sounding amp, but it's fairly complicated project because it involves welding and electronic skills to build, for achieving the best possible sound. The settings for the volume, gain and bass are good to have for a more fine tune of the amplifier and it runs from a $9 \mathrm{~V}$ Battery.

\section{REFERENCES}

[1] Operational Amplifier Speed and Accuracy Improvement: Analog Circuit Design with 
Structural Methodology (Vadim V. Ivanov, Igor M. Filanovsky) ISBN-13 1402025173.

[2] Audio Power Amplifier Design Handbook (Douglas Self) ISBN-13: 1136123652.

[3] Passive Components for Circuit Design (Ian Sinclair) ISBN- 13: 978-0750649339.

[4] Fundamentals of Electronics: Book 3: Active Filters and Amplifier Frequency Response (Thomas F. Schubert) ISBN 978-1627055666. 